\title{
Lung Function: Occupational Exposure to WoOd Dust
}

\author{
S. Baran ${ }^{1}$, K. Swietlik ${ }^{2}$, I. Teul ${ }^{3}$ \\ ${ }^{1}$ Faculty of Education, Sociology and Health Sciences, University of Zielona Gora, Poland; ${ }^{2}$ Clinic of Occupational Medicine, Poles, Zielona \\ Gora, Poland; ${ }^{3}$ Departament of Anatomy, Pomeranian Medical University, Szczecin, Poland
}

\begin{abstract}
Objectives: Occupational exposure to wood dust has been shown to cause several respiratory disorders, such as allergic rhinitis, chronic bronchitis, asthma, sino-nasal adenocarcinoma, and impairment of lung function. The aim of the study was to estimate lung function (in the woodworking industry) among workers employed by wood processing, who run the risk of being expose to wood dust.

Methods: The study concerns a group of 70 workers aged 24- 55. All the workers underwent general and laryngological examination. A group of 20 workers, working at the positions where dustiness exceeded TLV (threshold limit value) took X-ray of the chest and spirometry. The following parameters were measured: VC, IC, ERV, TV, BF, FEV 1 , FVC, PEF, $\mathrm{MEF}^{25-75}, \mathrm{FEV}_{1} \% \mathrm{FVC}, \mathrm{FEV}_{1} \% \mathrm{VC}$. The data are presented as means \pm SD and the authors applied references values according to ERS guidelines.

Results: The results show that there was no decline in $\mathrm{FEV}_{1}(3.7 \pm 0.7)$ and FVC $(4.5 \pm 0.8)$. Normal lung function was defined as $F E V_{1} / \mathrm{VC}$ ratio $\geq 0.7$. None of the tested workers had obstructive pattern in spirometry. The mean $\mathrm{FEV}_{1} \% \mathrm{VC}$ was $77.1 \pm 10.2$. These results suggest that wood dust exposure might not lead to significant pulmonary damage.

Conclusions: These data do not corroborate that wood dust plays significant role in lung function impairment. Future studies of respiratory health among workers exposed to wood dust are needed.
\end{abstract}

Key words: lung function, occupational exposure, wood dust, spirometry parameters

\section{INTRODUCTION}

In his occupational environment, man is exposed to a variety of health hazards that relate to the workplace and type of job. Woodworking involves a number of technology-related health hazards. Tools used in the woodworking industry produce not only noise and vibrations but also wood dust. Most wood dust enters the human body through the respiratory system. Occupational exposure to wood dust can be a cause of various respiratory disorders, such as allergic rhinitis, chronic bronchitis, asthma, sino-nasal adenocarcinoma and impairment of lung function. The harmful nature of dust depends upon, inter alia, the concentration, shape, size and chemical composition of dust particles $[1,2,3,4]$. It also depends upon man's individual char- acteristics - both genetic and acquired. Wood dust generated by industrial woodworking consists mainly of sub- $5 \mu \mathrm{m}$ particles, which mainly become trapped in the upper respiratory system. Particles with an aerodynamic diameter of under $5 \mu \mathrm{m}$ are especially hazardous: through sedimentation and diffusion, they infiltrate into the lower, non-ciliated, respiratory system where their half-life exceeds one month, and hence the removal rate is very slow. Prevention involves defining the maximum permissible concentration (MPC) of wood dust in the workplace and setting it as a standard enforced through legislative measures. In Poland, the assessment of occupational exposure to wood dust in the workplace is based on the measurements of airborne wood dust surrounding a person (total dust) and the wood dust depositing in alveoli (respirable dust). The measurements show whether MPC (maximum permissible concentration) or MEL (maximum exposure limit) or TLV (threshold limit value) is exceeded in any given workplace, i.e. whether hygienic standards are met or not $[5,6,7,8]$.

This purpose of this paper is to assess the lung function of those who are employed in woodworking jobs that involve exposure to wood dust.

\section{Material AND Methods}

The research involved seventy (70) male workers in a factory that specialises in the production of wooden frames for upholstered furniture. Basic demographic and anthropometric information was collected, such as their calendar age, work experience, smoking habits, chest circumference, body height and mass. The last two were used to calculate body mass index (BMI). The variables, work experience and BMI, were then categorised: BMI was categorised according to the WHO recommendations, while work experience was divided into short period (under 5 years) and long period (over 5 years).

All subjects had a general and laryngological checkup. Twenty of those workers, whose workplaces had excessive dust threshold limit values, took chest X-rays and spirometry (MES Lungtest 500, Krakow, Poland). The subjects were tested in a sitting position with a nose clip on. The following static and dynamic parameters were measured: vital capacity (VC), inspiratory capacity (IC), expiratory reserve volume (ERV), inspiratory reserve volume (IRV), tidal volume (TV), forced expiratory volume per second $\left(F E V_{1}\right)$, forced vital capacity (FVC), peak expiratory flow (PEF), max- 
imum expiratory flow at $75 \%, 50 \%$, and $25 \%$ of FVC $\left(\mathrm{MEF}^{25-75}\right)$, ratio of forced expiratory volume per second to forced vital capacity $\left(\mathrm{FEV}_{1} / \mathrm{FVC}\right.$ ratio), and ratio of forced expiratory volume per second to vital capacity $\left(\mathrm{FEV}_{1} / \mathrm{VC}\right.$ ratio). An assessment of the spirometry test results was preceded by an analysis of the parameters and diagrams attesting the quality of the testing, in accordance with the European Respiratory Society and the American Thoracic Society standards (ATS/ERS 2005, PTCHP 2006).

The occupational exposure was assessed on the basis of the measurements of airborne wood dust concentration in the workplaces by using the gravimetric method, in accordance with Directive 2004/37/EC. In addition, dust exposure indices were defined with regard to daily working hours and compared against the MPC values, as specified in the regulations by the Polish Ministry of Labour and Social Policy. In Poland, the MPC is 4 $\mathrm{mg} / \mathrm{m}^{3}$ for total wood dust without hardwood dust, and $2 \mathrm{mg} / \mathrm{m}^{3}$ for hardwood dust and mixed dust.

The data are presented as means \pm SD. The Shapiro-Wilk test was used to test the distribution of each variable with regard to normality, whereas the equality of variance was tested using the Levene's test.
Combinations of quality and linear predictors were analysed, with the use of dependent variables. A multivariate analysis of variance was applied to the normally distributed data, producing both univariate and multivariate results, while the non-parametric KruskalWallis one-way analysis of variance was applied for the other data. Likewise, Pearson's correlation coefficient was calculated for the normally distributed data and Spearman's rank correlation coefficient was calculated for the data with non-normal distribution. The level of statistically significant difference was set at 0.05 $(\mathrm{p}<0.05)$. All analyses were made using Statistica 8.0 software.

\section{RESULTS}

The subjects were on average 40.5 years old (between 24 and 55) and had an average work experience of 8.5 years (between 1 and 15). Most (65\%) fell into the 'long experience' category. The number of smokers was 16. Nearly $50 \%$ had proper body mass (BMI < $25)$. Obesity (BMI > 30) was found in 30\% of them. Their demographic and anthropometric characteristics are given in Table 1.

Table 1. Demographic characteristics of the subjects studied.

\begin{tabular}{|c|c|c|c|c|}
\hline & Mean & Minimum & Maximum & SD \\
\hline Age (years) & 42.3 & 24.00 & 55.00 & 10.4 \\
\hline Work experience (years) & 8.5 & 1.00 & 12.00 & 4.2 \\
\hline Height (cm) & 173.5 & 160.00 & 188.00 & 7.3 \\
\hline Body weight (kg) & 83.8 & 62.00 & 125.00 & 15.6 \\
\hline $\mathrm{BMI}\left(\mathrm{kg} / \mathrm{m}^{2}\right)$ & 27.1 & 20.02 & 40.35 & 5.0 \\
\hline Smokers (n) & 16.0 & & & \\
\hline
\end{tabular}

Table 2. Spirometry values.

\begin{tabular}{lcccc}
\hline & Mean & Min & Max & SD \\
\hline FEV $_{1}$ & 3.69 & 2.46 & 5.02 & 0.67 \\
FEV $_{1}$ (\% pred) & 99.0 & 62.4 & 127.7 & 14.9 \\
FVC & 4.54 & 2.92 & 5.79 & 0.82 \\
FVC (\%pred) & 99.7 & 75.6 & 118.6 & 10.8 \\
PEF & 7.38 & 4.01 & 13.58 & 2.53 \\
PEF (\%pred) & 85.0 & 53.2 & 147.1 & 22.0 \\
MEF75 & 6.93 & 3.10 & 13.15 & 2.46 \\
MEF75 (\%pred) & 93.0 & 60.2 & 166.9 & 23.7 \\
MEF50 & 5.44 & 3.42 & 8.36 & 1.57 \\
MEF50 (\%pred) & 110.3 & 73.3 & 172.4 & 23.7 \\
MEF25 & 2.86 & 1.63 & 4.41 & 0.97 \\
MEF25 (\%pred) & 133.7 & 67.1 & 189.6 & 23.7 \\
FEV ${ }_{1} \%$ FVC & 82.0 & 51.4 & 93.2 & 8.1 \\
FEV ${ }_{1} \%$ FVC (\%pred) & 102.9 & 91.9 & 120.6 & 11.1 \\
FEV ${ }_{1} \%$ VC & 77.1 & 51.0 & 92.3 & 10.2 \\
FEV $\%$ \%C (\%pred) & 96.4 & 74.8 & 115.7 & 13.8 \\
VC & 4.85 & 3.11 & 6.27 & 0.87 \\
VC (\%pred) & 102.9 & 84.2 & 125.2 & 13.8 \\
& & & & \\
\hline
\end{tabular}


Dust concentration in the workplaces ranged from $0.49 \mathrm{mg} / \mathrm{m}^{3}$ to $18.2 \mathrm{mg} / \mathrm{m}^{3}$. Softwood made up 60\% of the timber used in the factory. The highest concentration of wood dust, exceeding the MPC, was found in the workplaces where the wood was planed or sawn with chain and rotary saws. Twenty of the subjects, including 7 smokers among them, worked in this environment.

The general and laryngological check-ups and chest $\mathrm{X}$-rays did not reveal any illness-related changes in the subjects studied. The results of their spirometric assessments are shown in Table 2 . These results are given in absolute and relative values; the latter being the ratio of the actual value to the predicted value (reference value for gender, age, and height).

The values of vital capacity (VC) and forced vital capacity (FVC) fell within the range of $85-125 \%$ and $76-119 \%$, respectively, of the reference value. $95 \%$ of the subjects had the forced expiratory volume per second $\left(\mathrm{FEV}_{1}\right)$ ranging between $80-129 \%$ of the reference value. The worst relative result was recorded in the case of peak expiratory flow (PEF): nearly half of the subjects had results of less than $80 \%$ of the norm. The results exceeding $80 \%$ of the norm for $75 \%$, $50 \%$, and $25 \%$ of FVC (MEF $25-75 \%$ ) were recorded in the case of $73 \%, 95 \%$, and $96 \%$ of the population, respectively.

The subjects with long work experience were found to have lower absolute values of all the spirometric parameters, i.e. $\mathrm{FEV}_{1}$, FVC, PEF, MEF $25-75 \%$, VC, IC, $\mathrm{FEV}_{1} / \mathrm{FVC}, \mathrm{FEV}_{1} / \mathrm{VC}$, than their counterparts with shorter experience. Similarly, the non-smokers had higher absolute values of $\mathrm{FEV}_{1}$, PEF, MEF 75\%, MEF $25 \%, \mathrm{FEV}_{1} / \mathrm{FVC}$, and $\mathrm{FEV}_{1} / \mathrm{VC}$ than the smokers. A multivariate analysis of variance of the mean spirometric parameter absolute values did not find any statistically significant differences between the variables.

The values of correlation coefficients point to weak relations between the variables in question. A statistically significant $(p<0.05)$ negative correlation was found between the following variables: age and $\mathrm{FEV}_{1}$ $(\mathrm{r}=-0.54)$, age and FVC $(\mathrm{r}=-0.79)$, age and VC $(\mathrm{r}=$ -0.57), smoking and $\mathrm{FEV}_{1} / \mathrm{VC}(\mathrm{r}=-0.52)$. A significant positive correlation was found between: chest circumference and MEF 25\% ( $\mathrm{r}=0.51)$, BMI and MEF $25 \%(r=0.48)$, chest circumference and IC $(r=0.47)$, BMI and IC $(\mathrm{r}=0.54)$. No significant correlation was found between work experience and the values of lung function parameters.

\section{Discussion}

The relationship between occupational exposure to wood dust and decrease in lung function has long been studied, but the data collated so far are often inconclusive and contradictory $[9,10,11,12,13]$. The present study and its statistical analyses did not find any significant decrease in lung function in people exposed at work to the airborne mixture of softwood and hardwood dust.

None of the subjects had an obstructive pattern of spirometry. A referential method of detecting obturation is the analysis of $\mathrm{FEV}_{1} / \mathrm{VCmax}$ (Tiffeneau in- dex), VCmax being the maximum vital capacity recorded during any of the respiratory manoeuvres (VC or FVC). Alternatively, pseudo-Tiffeneau index is used $\left(\mathrm{FEV}_{1} / \mathrm{VC}\right)$. According to GOLD recommendations, for the purpose of obturation detection, the $\mathrm{FEV}_{1} / \mathrm{FVC}$ index should be lowered to below 0.7 $(70 \%)$. In healthy individuals, however, VC tends to be slightly higher than FVC, which, in the case of obstructive changes, may produce heightened values of the Tiffeneau index $(>70 \%)$. In the present study, we found that VC was indeed higher than FVC (Table 2). Therefore, we adopted the $\mathrm{FEV}_{1} / \mathrm{VC}<70 \%$ to detect obstructive changes. One ought to remember, however, that this is a simplified, fault-prone method. Adopting a constant lower limit of the norm for this index is at odds with the physiology of the respiratory system.

Obstructive changes may also cause decreased airflow in the final stage of expiration, so they may not be reflected as lower $\mathrm{FEV}_{1}$ or FVC values, but they may disturb the maximum expiratory flow at the level of $50 \%$ and $25 \%$ of FVC (MEF 50\% and MEF 25\%). However, such changes are of a non-specific character and the spread of these indices in healthy individuals is very high. Isolated disturbances in the maximum airflow do not necessarily point to obstructive changes. The values of MEF $50 \%$ lower than $60 \%$ of the reference value are regarded as a negative test result for small bronchi, which, with proper values of $\mathrm{FEV}_{1}$ and $\mathrm{FEV}_{1} / \mathrm{FVC}$, may signal potential future obturation of the airways. This study did not find any such cases.

Instead, poorer results were recorded in the case of maximum airflow at the level of $75 \%$ (MEF 75\%), i.e., the airflow rate at the early stages of expiration, which was confirmed by the results of PEF measurements, the so-called indirect index of airway patency. The subjects had lower values of the parameters which are effort-dependent, and this attests to the poorer performance of the upper airways, compared with the lower airways.

Spirometry test results can also point to restrictive changes. The possibility of restrictive pulmonary impairment was in this study defined as VC lower than $80 \%$ of the reference value, with no traces of obturation, i.e., with the proper $\mathrm{FEV}_{1} / \mathrm{VC}$ value. None of the subjects was found to have a suspected ventilation defect of a restrictive nature. However, a decrease in $\mathrm{VC}$ is not enough to ascertain volume restriction. Suspected restriction requires the total lung capacity to be measured by means of plethysmography.

Although this study did not find any negative effect of wood dust on lung function, further exploration in this field is essential. It is important to take account not only of dust concentration, particle size, and exposure time, but also of a variety of background and individual factors (e.g., specific sort of wood, wood dust related biohazards, or disease history), since they may also contribute significantly to the decreased efficiency of lung function.

\section{REFERENCES}

[1] Gripenback S, Lundgren L, Eklund A, Liden C, Skare L, Tornling G, Grunewald J. Accumulation of eosinophils and T-lymphocytes in the lungs after exposure to pinewood dust. Eur Respir J. 2005;2 5(1): 118-24. 
[2] Maatta J, Luukkonen R, Husgafvel-Pursiainen K, Alenius $\mathrm{H}$, Savolainen K. Comparison of hardwood and softwood dust-induced expression of cytokines and chemokines in mouse macrophage RAW 264.7 cells. Toxicology. 2006; 20; 218(1): 13-21.

[3] Maatta J, Lehto M, Leino M, Tillander S, Haapakoski R, Majuri ML, Wolff H, Rautio S, Welling I, Husgafvel-Pursiainen K, Savolainen K, Alenius H. Mechanisms of particle-induced pulmonary inflammation in a mouse model: exposure to wood dust. Toxicol Sci. 2006; 93(1): 96-104.

[4] Schlünssen V, Schaumburg I. Asthma, bronchitis and chronic obstructive pulmonary disease in occupational exposure to wood. Ugeskr Laeger 1998; 160(5): 609-15.

[5] Alwis U, Mandryk J, Hocking AD, Lee J, Mayhew T, Baker W. Dust exposures in the wood processing industry. Am Ind Hyg Assoc J. 1999; 60(5): 641-6.

[6] Carton M, Goldberg M, Luce D. Occupational exposure to wood dust. Health effects and exposure limit values. Rev Epidemiol Sante Publique 2002; 50(2): 159-78.

[7] Black N, Dilworth M, Summers N. Occupational exposure to wood dust in the British woodworking industry in 1999/2000. Ann Occup Hyg 2007; 51(3): 249-60.

[8] Scheeper B, Kromhout H. Boleij JSM. Wood-dust exposure during wood-working processes. Ann Occup Hygiene 1995; 39(2): 141-154.

[9] Mandryk J, Alwis KU, Hocking AD. Work-related symptoms and dose-response relationships for personal exposures and pulmonary function among woodworkers. Am J Ind Med 1999; 35(5): 481-90.
[10] Innocenti A, Ciapini C, Natale D, Nerozzi F, Pippi P, Selmi M. Longitudinal changes of pulmonary function in workers with high wood dust exposure levels. Med Lav 2006; 97(1): 30-5.

[11] Lion SH, Cheng SY, Lai FM, Yang JL. Respiratory symptoms and pulmonary function in mill workers exposed to wood dust. Am J Ind Med 1996; 30 (3): 293-9

[12] Lion SH, Yang JL, Cheng SY, Lai FM. Respiratory symptoms and pulmonary function among wood dust-exposed joss stick workers. Int Arch Occup Environ Health 1996; 68: 154-160.

[13] Bohadana A, Massin N, Wild P, Toamain J, Engel S, Goutet P. Symptoms, airway responsiveness, and exposure to dust in beech and oak wood workers. Occup Environ Med 2000; 57(4): 268-273.

Address for correspondence:

Sylwia Baran

Department of Physical Education

University of Zielona Góra

Al. Wojska Polskiego 69

65-762 Zielona Góra

Poland

Phone: +48683287835

Mobile: +48 605435252

E-mail: sbaran@ipp.uz.zgora.pl 